\title{
Single fraction radiotherapy versus multiple fraction radiotherapy for bone metastases in prostate cancer patients: comparative effectiveness
}

This article was published in the following Dove Press journal:

Cancer Management and Research

25 November 2014

Number of times this article has been viewed

\author{
Frederick Yoon' \\ Gerard C Morton ${ }^{2}$ \\ 'Simcoe Muskoka Regional Cancer \\ Centre, Royal Victoria Regional \\ Health Centre, Barrie, ON, Canada; \\ ${ }^{2}$ Department of Radiation Oncology, \\ University of Toronto, Toronto, \\ ON, Canada
}

\begin{abstract}
External beam radiotherapy (EBRT) is an effective treatment for symptomatic bone metastases from a variety of primary malignancies. Previous meta-analyses and systematic reviews have reported on the efficacy of EBRT on bone metastases from multiple primaries. This review is focused on the comparative effectiveness of single fraction radiotherapy versus multiple fraction radiotherapy for bone metastases in prostate cancer patients.
\end{abstract}

Keywords: radiotherapy, bone, metastases, prostate, comparative effectiveness

\section{Introduction}

In 2014 there will be an estimated 233,000 new cases of prostate cancer and 29,480 deaths from prostate cancer in the USA. ${ }^{1}$ Approximately $50 \%$ of advanced prostate cancer patients develop bone metastases. ${ }^{2,3}$ Treatment options for prostate cancer- related bone metastases include palliative external beam radiotherapy (EBRT), medical management with analgesics, radionuclides, and systemic treatments such as androgen deprivation therapy, bisphosphonates, and chemotherapy. Palliative EBRT is an effective treatment option for pain control from symptomatic bone metastases. Multiple randomized controlled studies, meta-analyses, and systematic reviews have all shown equivalence in pain response between single fraction (SF) radiotherapy and multiple fraction (MF) radiotherapy in cancer patients with bone metastases from a variety of primary malignancies. ${ }^{4-8}$ We conducted a review of the comparative effectiveness of single versus multifractionated radiotherapy for bone metastases from prostate cancer.

\section{Methods}

An Internet literature search was conducted using the PubMed online biomedical search engine for literature published between January 2000 and April 2014 using the following search terms: bone, metastasis or metastases, radiation or radiotherapy, prostate, fraction, single, and multiple. The search language was restricted to English. Another Internet search of the Medical Literature Analysis and Retrieval System Online (MEDLINE); the US National Cancer Institute's cancer literature database on PubMed (formerly CancerLit); and the Cochrane Library was conducted to identify randomized controlled trials published during the same time period, using the following Medical Subject Heading (MeSH) terms: Bone Neoplasms/radiotherapy, Bone Neoplasms/ secondary, and Dose Fractionation.

Eligible published studies were also identified from reference lists of retrieved papers and review articles. Included were all published randomized controlled trials
Correspondence: Frederick Yoon Simcoe Muskoka Regional Cancer Centre, Royal Victoria Regional Health Centre, 20I Georgian Drive, Barrie, ON, L4M 6M2, Canada

Tel + I 7057289090

Email yoonf@rvh.on.ca 
comparing SF or MF schedules for the treatment of bone metastases. Only trials using conventional EBRT were included. Trials involving the use of hemi-body radiotherapy and radionuclides were excluded, as were studies involving patients with complicated bone metastases causing spinal cord compression, cauda equina syndrome, or pathological fractures.

\section{Results}

A total of seventeen randomized controlled studies were found that fit our inclusion criteria. Table 1 lists these seventeen studies. Only three studies broke down their results by both fractionation arm and primary malignancy. There are no published randomized controlled studies involving prostate cancer patients with sufficient patient numbers to enable a statistically valid comparative effectiveness analysis between SF and MF regimens in prostate cancer patients.

\section{Response rates}

In the updated systematic review published in 2012 by Chow et al, the overall response rates for all patients with bone metastases from various primary malignancies were similar, with 1,696 of $2,818(60 \%)$ patients in the SF arm and 1,711 of $2,799(61 \%)$ patients in the MF arm achieving a response. ${ }^{8}$ Using an intention-to-treat analysis, 620 of 2,641 (23\%) SF patients and 634 of 2,622 (24\%) of MF patients reported a complete response. There is little convincing evidence that the pain response rate from prostate metastases differs from that of other primary malignancies. Some evidence suggests a higher response rate from prostate cancer than other primaries, ${ }^{9-16}$ with the possible exception of breast cancer, while other studies have not supported this. ${ }^{2,17-20}$ In general, however, results from randomized control studies have not been broken down simultaneously by both primary malignancy and fractionation schedules to elucidate if there is a difference in response rates specifically for prostate cancer

Table I Randomized controlled studies comparing single versus multiple fractions of radiotherapy in bone metastases

\begin{tabular}{|c|c|c|c|c|c|}
\hline Author (country) & Year & Treatment arms & $\begin{array}{l}\text { Number } \\
\text { of patients }\end{array}$ & $\begin{array}{l}\text { Number of prostate } \\
\text { cancer patients (\%) }\end{array}$ & $\begin{array}{l}\text { Breakdown of results for } \\
\text { prostate cancer patients }\end{array}$ \\
\hline $\operatorname{Cole}^{25}$ (UK) & 1989 & $8 \mathrm{~Gy} / \mathrm{I}$ v versus $24 \mathrm{~Gy} / 6 \mathrm{~F}$ & 29 & $4(14 \%)$ & No \\
\hline Amouzegar-Hashemi et $\mathrm{al}^{34}$ (Iran) & 2008 & $8 \mathrm{~Gy} / \mathrm{I} \mathrm{F}$ versus $30 \mathrm{~Gy} / \mathrm{l} 0 \mathrm{~F}$ & 70 & $10(14 \%)$ & No \\
\hline Foro Arnalot et $\mathrm{a}^{27}$ (Spain) & 2008 & $8 \mathrm{~Gy} / \mathrm{I} \mathrm{F}$ versus $30 \mathrm{~Gy} / 10 \mathrm{~F}$ & 160 & $40(25 \%)$ & No \\
\hline Gaze et $\mathrm{al}^{2}$ (UK) & 1997 & $10 \mathrm{~Gy} / \mathrm{I} \mathrm{F}$ versus $22.5 \mathrm{~Gy} / 5 \mathrm{~F}$ & 265 & $54(20 \%)$ & No \\
\hline Hartsell et $\mathrm{al}^{21}$ (RTOG 97।4; USA) & 2005 & $8 \mathrm{~Gy} / \mathrm{I} \mathrm{F}$ versus $30 \mathrm{~Gy} / \mathrm{I0} \mathrm{F}$ & 898 & $445(50 \%)^{\mathrm{a}}$ & No \\
\hline Kaasa et $\mathrm{a}^{28}$ (Norway/Sweden) & 2006 & $8 \mathrm{~Gy} / \mathrm{I} \mathrm{F}$ versus $30 \mathrm{~Gy} / 10 \mathrm{~F}$ & 376 & $139(37 \%)$ & No \\
\hline Nielsen et $\mathrm{a}^{26}$ (Denmark) & 1998 & $8 \mathrm{~Gy} / \mathrm{I} \mathrm{F}$ versus $20 \mathrm{~Gy} / 4 \mathrm{~F}$ & 241 & $80(33 \%)$ & No \\
\hline $\begin{array}{l}\text { Steenland et al }{ }^{10} \text { (The Dutch Bone } \\
\text { Metastasis Study; the Netherlands) }\end{array}$ & 1999 & $8 \mathrm{~Gy} / \mathrm{I} \mathrm{F}$ versus $24 \mathrm{~Gy} / 6 \mathrm{~F}$ & $1,|7|$ & $\begin{array}{l}\text { Absolute number } \\
\text { of prostate patients } \\
\text { not given }(23 \%)\end{array}$ & Yes \\
\hline Sande et al ${ }^{22}$ (Norway) $)^{\mathrm{b}}$ & 2009 & $8 \mathrm{~Gy} / \mathrm{I} \mathrm{F}$ versus $30 \mathrm{~Gy} / 10 \mathrm{~F}$ & 180 & $53(30 \%)$ & Partiallyc \\
\hline Price et $\mathrm{al}^{13}$ (UK) & 1986 & $8 \mathrm{~Gy} / \mathrm{I} \mathrm{F}$ versus $30 \mathrm{~Gy} / \mathrm{l} 0 \mathrm{~F}$ & 288 & $24(8 \%)$ & Partially ${ }^{d}$ \\
\hline $\begin{array}{l}\text { Roos et al }{ }^{18} \text { (TROG 96.05; Australia/ } \\
\text { New Zealand/UK) }\end{array}$ & 2005 & $8 \mathrm{~Gy} / \mathrm{I} \mathrm{F}$ versus $20 \mathrm{~Gy} / 5 \mathrm{~F}$ & 272 & $79(29 \%)$ & Partiallye \\
\hline Sarkar et al ${ }^{35}$ (India) & 2002 & $8 \mathrm{~Gy} / \mathrm{I} \mathrm{F}$ versus $30 \mathrm{~Gy} / 10 \mathrm{~F}$ & 73 & $4(5 \%)$ & No \\
\hline $\begin{array}{l}\text { Bone Pain Trial Working Party }{ }^{24} \\
\text { (UK/New Zealand) }\end{array}$ & 1999 & $\begin{array}{l}8 \mathrm{~Gy} / \mathrm{I} \text { F versus } 30 \mathrm{~Gy} / 10 \mathrm{~F} \\
\text { or } 20 \mathrm{~Gy} / 5 \mathrm{~F}\end{array}$ & 765 & $260(34 \%)$ & No \\
\hline van der Linden" (the Netherlands) & 2006 & $8 \mathrm{~Gy} / \mathrm{I}$ versus $24 \mathrm{~Gy} / 6 \mathrm{~F}$ & 320 & $74(23 \%)$ & Yes \\
\hline Safwat et $\mathrm{al}^{36}$ (Egypt) & 2007 & $\begin{array}{l}8 \mathrm{~Gy} / \mathrm{I} \mathrm{F} \text { versus } 30 \mathrm{~Gy} / 10 \mathrm{~F} \\
\text { versus } 20 \mathrm{~Gy} / 5 \mathrm{~F}\end{array}$ & 60 & $4(7 \%)$ & No \\
\hline Hamouda et al ${ }^{9}$ (Egypt) & 2007 & $8 \mathrm{~Gy} / \mathrm{I} \mathrm{F}$ versus $40 \mathrm{~Gy} / 20 \mathrm{~F}$ & 102 & $18(18 \%)$ & Yes \\
\hline El-Shenshawy et $\mathrm{a}^{23}$ (Egypt) & 2006 & $\begin{array}{l}8 \mathrm{~Gy} / \mathrm{I} \mathrm{F} \text { versus } 30 \mathrm{~Gy} / 10 \mathrm{~F} \\
\text { or } 20 \mathrm{~Gy} / 5 \mathrm{~F}\end{array}$ & 150 & $43(29 \%)$ & Partially ${ }^{g}$ \\
\hline
\end{tabular}

Notes: aHartsell did not report specifically on the number of prostate cancer patients, but only breast and prostate patients were included in this study and 445 patients were male in this study; ${ }^{b}$ this study is a long-term follow-up of the subset of Norwegian patients in the larger study by Kaasa et al (2006); 'Sande et al reported retreatment rates by primary tumor; dalthough no breakdown was given by fractionation and tumor type, the publication stated that "pain relief was independent of the histology of the primary tumour"; exploratory multifactor analyses were carried out, adjusting for primary cancer (lung/prostate/breast/other), with no significant changes in the results and conclusions; 'this study was a subset of the Dutch Bone Metastasis Study for patients who survived more than 52 weeks; sthis paper reported the median times to pain progression by primary malignancy.

Abbreviations: Gy, Gray; F, fraction; RTOG, Radiation Therapy Oncology Group; TROG, Trans Tasman Radiation Oncology Group. 
patients between single and multifractionated regimens. Exceptions do exist, however. One study from Egypt by Hamouda et al reported a $100 \%$ response rate to palliative radiotherapy for prostate patients in both the SF and MF arms. ${ }^{9}$ This study had only 18 prostate cancer patients, so no conclusions between SF and MF regimens can be made from this relatively small study, especially with a $100 \%$ response rate for both fractionation schemes. There was a significantly lower response rate for lung cancer patients (61.9\%) in comparison to patients with breast (91.8\%) and prostate $(100 \%)$ cancer $(P<0.05$ for both comparisons). The Dutch Bone Metastasis Study by Steenland et al also provided results by fractionation arm and primary malignancy, but did not provide statistical analysis by primary tumor type, probably because of small numbers for individual primary tumors. ${ }^{10}$ In a subset analysis of patients living more than 1 year in the Dutch Bone Metastasis Study reported by van der Linden et al, results were analyzed by primary malignancy. ${ }^{11}$ Seventy-four prostate patients were included in this analysis (34 patients in the 8 Gray [Gy]/1 fraction [F] arm $[8 \mathrm{~Gy} / 1 \mathrm{~F}$ arm $]$ and 40 patients in the $24 \mathrm{~Gy} / 6 \mathrm{~F}$ arm [24 Gy/6 F] arm), and the pain response rates were similar at $85 \%$ and $90 \%(P=0.11)$ for the $8 \mathrm{~Gy} / 1 \mathrm{~F}$ and $24 \mathrm{~Gy} / 6 \mathrm{~F}$ arms, respectively. This subset analysis was underpowered to draw any firm conclusions between SF and MF regimens for prostate cancer patients. Price et al did not provide a specific breakdown of results for prostate cancer patients but did state in their paper that "pain relief was independent of the histology of the primary tumour". ${ }^{13}$

Hartsell et al reported the results of Randomized Trial of Palliative Radiation Therapy For Osseous Metastases Study 9714 (RTOG 9714), which randomized 898 patients with bone metastases from breast or prostate cancer to receive either 8 Gy as a SF $(8 \mathrm{~Gy} / 1 \mathrm{~F})$ or $30 \mathrm{~Gy}$ in ten fractions $(30 \mathrm{~Gy} / 10 \mathrm{~F}) .{ }^{21}$ Half of the patients had a primary diagnosis of prostate cancer. A complete response was defined as having no pain at 3 months after radiotherapy, a partial response was defined as a pain score that was at least two points lower than the baseline score, a stable response was defined as a one-point change in pain score (either worse or better), and progression was defined as a pain score that was at least two points higher than the baseline score. The complete and partial response rates at 3 months for the 288 patients in the $8 \mathrm{~Gy} / 1 \mathrm{~F}$ arm were $15 \%$ (44 patients) and 50\% (143 patients), respectively; for the 285 patients in the $30 \mathrm{~Gy} / 10 \mathrm{~F}$ arm the complete and partial response rates were 18\% (51 patients) and 48\% (137 patients), respectively ( $P=0.6)$.
The Dutch Bone Metastasis Study, which randomized patients between 8 Gy as a SF ( 8 Gy/1 F) and $24 \mathrm{~Gy}$ in six fractions ( $24 \mathrm{~Gy} / 6 \mathrm{~F})$, analyzed some of its results by primary tumor site but did not provide statistical analysis by primary tumor, perhaps because of small numbers for individual primary sites. The study did state, however, that there was no indication that the treatment effect of fractionation was dependent on tumor type. ${ }^{10}$ The pain response rates in prostate cancer patients were $77 \%(96 / 124)$ for the $24 \mathrm{~Gy} / 6 \mathrm{~F}$ arm and $78 \%(95 / 121)$ for the $8 \mathrm{~Gy} / 1 \mathrm{~F}$ arm. The complete response rates for prostate cancer patients were $44 \%(55 / 125)$ and $38 \%$ (46/122) for the $24 \mathrm{~Gy} / 6 \mathrm{~F}$ arm and $8 \mathrm{~Gy} / 1 \mathrm{~F}$ arm, respectively. There was a higher rate of response and complete response for breast and prostate patients compared to lung and other primary tumors. The response rates for breast and prostate patients were $76 \%$ and $78 \%$, respectively, compared to $60 \%$ for lung patients and $62 \%$ for all other primary diagnoses analyzed together. The complete response rates for breast and prostate patients were $44 \%$ and $41 \%$, respectively, compared to $24 \%$ for lung patients and $16 \%$ for other primary sites.

Therefore, based on the limited data in the literature, there do not appear to be any apparent differences in response rates to single versus multifractionated radiotherapy for bone metastases from prostate cancer, which is consistent with bone metastases from other primary sites in general.

Bone metastases causing neuropathic pain are considered to be complicated bone metastases, and perhaps require a larger dose of radiation to control them. Trans-Tasman Radiation Oncology Group trial (TROG 96.05) compared 8 Gy/1 F and $20 \mathrm{~Gy} / 5 \mathrm{~F}$ in 272 patients with neuropathic pain from bone metastases. ${ }^{18}$ Prostate cancer patients represented $29 \%$ of the population. The overall response rates for $8 \mathrm{~Gy} / 1 \mathrm{~F}$ and $20 \mathrm{~Gy} / 5 \mathrm{~F}$ were $53 \%$ and $61 \%$, respectively $(P=0.18)$, with complete response rates of $26 \%$ and $27 \%$, respectively $(P=0.89)$. The estimated median time to treatment failure (TTF) was 2.4 months (95\% confidence interval [CI]: 2.0-3.3 months) and 3.7 months (95\% CI: 3.1-5.9 months), respectively, for $8 \mathrm{~Gy} / 1 \mathrm{~F}$ and $20 \mathrm{~Gy} / 5 \mathrm{~F}$. There was a trend to shorter TTF in the SF arm with a hazard ratio of $1.35(P=0.056)$. There were no significant differences in the rates of retreatment, spinal cord compression, or pathological fracture between the two arms. Exploratory analyses were carried out adjusting for treatment site (spine versus non-spine) and for primary malignancy (lung/prostate/breast/other), with no changes in the conclusions by treatment arm. Therefore, it appears that even for bone metastases causing neuropathic pain, SF regimens are equivalent to MF regimens in overall and complete 
response rates. However, there may be a trend toward earlier treatment failure for a SF regimen for neuropathic pain.

\section{Retreatment rates}

The meta-analysis by Chow et al reported a significantly higher number of retreatments for SF patients, 473 of 2,323 (20\%), compared to MF patients, 178 of 2,309 (8\%), $(P<0.00001) .{ }^{8}$ RTOG 9714 reported a statistically significant difference in retreatment rates between the two arms with 3 -year retreatment rates of $18 \%$ (76/449 patients) in the $8 \mathrm{~Gy} / 1 \mathrm{~F}$ arm and 9\% (33/432 patients) in the $30 \mathrm{~Gy} / 10 \mathrm{~F}$ $\operatorname{arm}(P<0.001) .{ }^{21}$ Most of the retreatments were given in the first 9 months after the initial radiotherapy, and retreatments were rarely delivered after 1 year of the initial treatment. Sande et al reported retreatment rates by primary tumor and the retreatment rates for prostate cancer patients undergoing $8 \mathrm{~Gy} / 1 \mathrm{~F}$ was $33 \%$ (9/27 patients) versus $12 \%$ (3/26 patients) in those undergoing $30 \mathrm{~Gy} / 10 \mathrm{~F}^{22}$ However, the numbers were too small for a valid statistical comparison between the two arms. Furthermore, multiple biases may lead to a higher and earlier retreatment rate following a SF of radiotherapy.

\section{Response duration}

There is some evidence to support the belief that prostate patients have a longer time to pain progression than other primaries, with the exception of breast cancer. ${ }^{11,13-16}$ El-Shenshawy et al found a median time to progression of 32 weeks, 18 weeks, 9 weeks, and 6 weeks for breast, prostate, lung, and other cancers, respectively $(P=0.0001) .{ }^{23}$ Pain progression was defined in that study as a return to the initial pain score or higher. However, the study did not analyze time to progression for prostate cancer patients between the different fractionation groups. Gaze et al had $20 \%$ of patients in their study with prostate cancer, and reported no difference in duration of pain control between $10 \mathrm{~Gy} / 1 \mathrm{~F}$ and $22.5 \mathrm{~Gy} / 5 \mathrm{~F}$ (a median of 13.5 weeks and 14 weeks, respectively). ${ }^{2}$ Results were not broken down by primary malignancy. Price et al reported no difference in the onset or duration of pain relief between $8 \mathrm{~Gy} / 1 \mathrm{~F}$ and $30 \mathrm{~Gy} / 10 \mathrm{~F}$, and pain relief was independent of the histology of the primary malignancy. ${ }^{13}$ These results are consistent with other randomized controlled studies that showed no difference in how quickly symptoms resolved or in the duration of pain relief, when a SF regimen was compared to a MF regimen., 3-11,24-26

The Dutch Bone Metastasis Study reported progression rates of $53 \%(51 / 96)$ and $61 \%$ (58/95) for the $24 \mathrm{~Gy} / 6 \mathrm{~F}$ and $8 \mathrm{~Gy} / 1 \mathrm{~F}$ arms, respectively, but no statistical analysis for this difference was provided. ${ }^{10}$ A subset analysis of the Dutch Bone
Metastasis Study was performed on patients who survived more than 1 year to see if there was an impact on fractionation schedules on pain control in long-term survivors with bone metastases. ${ }^{11}$ There were 320 patients who survived more than 1 year, and 74 (23\%) of these patients had prostate cancer. For all 320 patients, $87 \%$ responded to $\mathrm{SF}$ and $85 \%$ to $\mathrm{MF}$ $(P=0.54)$. Complete response was seen in $62 \%$ of SF patients and $48 \%$ of $\mathrm{MF}$ patients $(P=0.07)$. The mean time to response was 4 weeks in both SF and MF patients. Mean duration of response was 29 weeks for SF patients (median duration 35 weeks) and 30 weeks for MF patients (median duration 42 weeks). Progressive pain was reported in 55\% of SF patients who responded and in 53\% of MF patients who responded. For patients who experienced progressive pain, the mean time to progression after a response was 17 weeks for SF patients and 18 weeks for MF patients. Therefore, even in patients with a good prognosis, which includes many breast and prostate cancer patients, there does not appear to be any difference in the duration of response after SF and MF regimens.

Sande et al reported that there was no significant difference between $8 \mathrm{~Gy} / 1 \mathrm{~F}$ and $30 \mathrm{~Gy} / 10 \mathrm{~F}$ in time to re-irradiation. ${ }^{22}$ Most of the re-irradiations, $64.5 \%$ for the $30 \mathrm{~Gy} / 10 \mathrm{~F}$ arm and $63.4 \%$ for the $8 \mathrm{~Gy} / 1 \mathrm{~F}$ arm, were given within the first 9 months. This suggests that the duration of pain relief was similar for the two treatment regimens, in accordance with other studies. ${ }^{10,24}$ Receiving 8 Gy/1 F may not make it more likely that physicians will retreat patients earlier. These findings may indicate that physicians do not use a lower clinical threshold of pain for retreatment after SF radiotherapy compared to MF radiotherapy.

The findings by Sande et al are contrary to those found in the Dutch Bone Metastasis Study. ${ }^{10}$ The Sande et al study reported a $25 \%(147 / 579)$ retreatment rate for the $8 \mathrm{~Gy} / 1 \mathrm{~F}$ arm and a $7 \%(41 / 578)$ retreatment rate in the $24 \mathrm{~Gy} / 6 \mathrm{~F}$ arm. Prostate patients had a retreatment rate of $22 \%(29 / 129)$ in the $8 \mathrm{~Gy} / 1 \mathrm{~F}$ arm and an $11 \%(15 / 138)$ retreatment rate in the $24 \mathrm{~Gy} / 6 \mathrm{~F}$ arm. Retreatment was demonstrated to occur earlier in pain progression in the $8 \mathrm{~Gy} / 1 \mathrm{~F}$ arm (at an average of 14 weeks) compared to 23 weeks in the multifraction group $(P<0.0001)$. The pain score preceding retreatment was higher in the multifraction arms at 7.52/10 compared to $6.82 / 10$ in the SF arm. This difference suggests that physicians may use a higher patient threshold of pain before retreating a patient who initially underwent a MF treatment.

\section{Toxicity}

RTOG 9714 reported that more patients had acute grades 2-4 toxicities in the $30 \mathrm{~Gy} / 10 \mathrm{~F}$ arm (17\%) than in the 
$8 \mathrm{~Gy} / 1 \mathrm{~F}$ arm (10\%) (difference $=7 \% ; 95 \% \mathrm{CI}=3 \%$ to $12 \%$; $P=0.002) .{ }^{21}$ The most common toxicity was gastrointestinal toxicity and accounted for approximately half of all acute side effects. Two patients, both of whom received $30 \mathrm{~Gy} / 10 \mathrm{~F}$, had grade 4 acute toxicities (one with emesis and one with neutropenia). The incidence of $\geq$ grade 2 late toxicity was $4 \%$ in both arms. Four patients, two in each treatment group, experienced late grade 3 toxicity. In a subset analysis of the RTOG 9714 trial looking at vertebral body metastases, 235 of 909 total patients $(26 \%)$ had vertebral body metastases. No differences were found in terms of pain relief $(62 \%$ for $30 \mathrm{~Gy} / 10 \mathrm{~F}$ and $70 \%$ for $8 \mathrm{~Gy} / 1 \mathrm{~F}$; $P=0.59$ ), but significant differences in acute grade $2-4$ toxicity $(20 \%$ and $10 \%$ for $30 \mathrm{~Gy} / 10 \mathrm{~F}$ and $8 \mathrm{~Gy} / 1 \mathrm{~F}$, respectively; $P=0.01$ ) and acute grade $2-4$ gastrointestinal toxicity (14\% and $6 \%$, respectively; $P=0.01$ ) were observed at 3 months, with lower toxicities seen in the patients treated with SF. Late toxicity was rare and no spinal cord myelopathy was recorded.

Foro Arnalot et al and Kaasa et al also reported more cases of acute toxicity in MF patients, but did not provide specific data on prostate cancer patients. ${ }^{27,28}$ Acute side effects can include nausea/vomiting, diarrhea, fatigue, and radiation dermatitis. Roos et al reported a worse pain flare in SF patients; ${ }^{18}$ however, no other randomized controlled study has reported on pain flares. Acknowledging these exceptions, the meta-analysis by Chow et al did not find any differences in acute toxicities between SF and MF patients in any other study. ${ }^{8}$

The systematic review by Chow et al reported no statistically significant differences in pathological fracture or spinal cord compression rates between SF and MF regimens. ${ }^{8}$ The Dutch Bone Metastasis Study provided fracture rates by both primary malignancy and fractionation, and reported the higher fracture rate in prostate cancer patients treated with $8 \mathrm{~Gy} / 1 \mathrm{~F}$ of $5 \%$ (7/129) compared to $2 \%(3 / 138)$ in patients treated with $24 \mathrm{~Gy} / 6 \mathrm{~F}$, but did not provide a statistical analysis of this. ${ }^{10}$

\section{Cost-effectiveness}

Various studies have reported on the economic advantage of SF over MF regimens. ${ }^{10,29-32}$ In the Dutch Bone Metastasis Study the estimated cost of radiotherapy, including retreatments and nonmedical costs, was significantly lower for the SF regimen than for the MF regimen ( $\$ 2,438$ [US dollars] versus $\$ 3,311, P<0.001) .{ }^{31}$ The saving of radiotherapy capacity was considered a major economic advantage of the $\mathrm{SF}$ regimen. No differences were found between the SF and MF schedules in life expectancy (43.0 versus 40.4 weeks; $P=0.20)$ or quality-adjusted life expectancy (17.7 versus 16.0 weeks; $P=0.21$ ). Another consideration is that the retreatment rate in the Dutch Bone Metastasis Study was four times higher in the SF arm, which is considerably higher than seen in the latest systematic review by Chow et al, ${ }^{8}$ which reported a two and six-tenths times higher rate of retreatment for patients treated with a SF compared to MFs. The higher rate of retreatment seen in the Dutch Bone Metastasis Study would tend to decrease the economic advantages of SF radiotherapy in bone metastases. Despite this, an economic advantage was still seen.

Konski et al published an analysis of the RTOG 9714 study using a Markov model to evaluate the cost-effectiveness of $30 \mathrm{~Gy} / 10 \mathrm{~F}$ compared with $8 \mathrm{~Gy} / 1 \mathrm{~F}^{29}$ The mean cost and quality-adjusted survival in months for the $8 \mathrm{~Gy} / 1 \mathrm{~F}$ regimen were $\$ 998$ (US dollars) and 7.26 months, and $\$ 2,316$ (US dollars) and 9.53 months for the $30 \mathrm{~Gy} / 10 \mathrm{~F}$ regimen. The incremental cost-effectiveness ratio was $\$ 6,973$ US dollars/ quality-adjusted life year, in favor of the SF regimen. This means that it only costs $\$ 6,973$ (US dollars) for each qualityadjusted life year using a $\mathrm{SF}$ regimen to treat bone metastases compared to using a MF regimen.

A cost-effectiveness analysis of TROG 96.05 showed that the $8 \mathrm{~Gy} / 1 \mathrm{~F}$ regimen, including retreatments, costs $\$ 222$ (Australian dollars) and that the $20 \mathrm{~Gy} / 5 \mathrm{~F}$ regimen costs \$724 (Australian dollars). ${ }^{30}$

\section{Discussion}

Janjan et al generated a therapeutic guideline for the treatment of bone metastases for the American College of Radiology and recommended SF radiotherapy because of its similar pain response, no differences in survival, better cost-effectiveness, and more convenience compared with MFs. ${ }^{3}$ A guideline by the American Society for Radiation Oncology similarly recommended a SF for uncomplicated bone metastases. ${ }^{33}$ Based on the limited data looking exclusively at prostate cancer patients we would recommend the same, namely that a SF of radiotherapy be the standard treatment for uncomplicated bone metastases from prostate cancer. There is some evidence from TROG 96.05 that bone metastases causing neuropathic pain may have a shorter TTF, but this difference was not statistically significant and there were no differences in the overall and complete response rates between $8 \mathrm{~Gy} / 1 \mathrm{~F}$ and $20 \mathrm{~Gy} / 5 \mathrm{~F}{ }^{18}$ Prostate cancer patients with bone metastases may have a better prognosis, along with breast cancer patients, compared to patients with bone metastases from other primaries, thus some believe that a MF regimen can produce longer-lasting pain relief in these better prognosis patients. However, the available evidence indicates that the duration of pain relief is 
similar between SF and MF regimens, including in patients with a good prognosis who live for more than a year. ${ }^{11} \mathrm{~A}$ SF regimen should be used for all uncomplicated bone metastases from prostate cancer, especially in patients who have a poorer prognosis, poor performance status, reside far from a cancer center, have difficulty traveling to and from treatments, and/or receive treatments in cancer centers with long wait times.

Although the RTOG 9714 study focusing exclusively on breast and prostate patients is one of the few studies that found a difference in radiation-related toxicities between SF and MF regimens, most studies have not found significant differences in toxicity between SF and MF treatments. There is no fundamental reason to expect the radiation-related side effects experienced for prostate cancer patients to be substantially different than those with other primary malignancies. However, even if there were a difference in toxicities, a SF regimen would be preferable due to the lower reported rates of radiotherapy side effects for a SF.

The costs of radiotherapy can differ between jurisdictions, but studies from three countries on three continents have consistently shown a cost-effectiveness advantage to SF regimens. ${ }^{29-31}$ Healthcare costs should not play a disproportionate role in treatment decisions, but are still an important consideration, and favor SF regimens.

\section{Conclusion}

There are no published randomized controlled studies involving prostate cancer patients with sufficient patient numbers and statistical analyses to draw any firm conclusions on the comparative effectiveness of SF and MF radiotherapy regimens specifically for bone metastases in prostate cancer patients. An individual patient meta-analysis of prostate cancer patients from previously-published randomized controlled studies may help to establish the comparative effectiveness of SF and MF regimens in this population of patients. Despite this, the available evidence supports the use of SF radiotherapy as a standard for all uncomplicated bone metastases from prostate cancer.

\section{Acknowledgment}

The authors would like to acknowledge the help of Camille Coles of the Royal Victoria Regional Health Centre Health Library for her help in conducting a literature search and gathering studies used in this review.

\section{Disclosure}

The authors report no conflicts of interest in this work.

\section{References}

1. http://www.cancer.gov [homepage on the Internet]. Prostate cancer. National Cancer Institute; 2014. Available from: http://www.cancer. gov/cancertopics/types/prostate. Accessed May 31, 2014.

2. Gaze MN, Kelly CG, Kerr GR, et al. Pain relief and quality of life following radiotherapy for bone metastases: a randomised trial of two fractionation schedules. Radiother Oncol. 1997;45(2):109-116.

3. Janjan N, Lutz ST, Bedwinek JM, et al. Therapeutic guidelines for the treatment of bone metastasis: a report from the American College of Radiology Appropriateness Criteria Expert Panel on Radiation Oncology. J Palliat Med. 2009;12(5):417-426.

4. Chow E, Harris K, Fan G, Tsao M, Sze WM. Palliative radiotherapy trials for bone metastases: a systematic review. J Clin Oncol. 2007;25(11):1423-1436.

5. McQuay HJ, Collins SL, Carroll D, Moore RA. Radiotherapy for the palliation of painful bone metastases. Cochrane Database Syst Rev. 2000;(2):CD001793.

6. Sze WM, Shelley MD, Held I, Wilt TJ, Mason MD. Palliation of metastatic bone pain: single fraction versus multifraction radiotherapy - a systematic review of randomised trials. Clin Oncol ( $R$ Coll Radiol). 2003;15(6):345-352.

7. Wu JS, Wong R, Johnston M, Bezjak A, Whelan T; Cancer Care Ontario Practice Guidelines Initiative Supportive Care Group. Meta-analysis of dose-fractionation radiotherapy trials for the palliation of painful bone metastases. Int J Radiat Oncol Biol Phys. 2003;55(3):594-605.

8. Chow E, Zeng L, Salvo N, Dennis K, Tsao M, Lutz S. Update on the systematic review of palliative radiotherapy trials for bone metastases. Clin Oncol (R Coll Radiol). 2012;24(2):112-124.

9. Hamouda WE, Roshdy W, Teema M. Single versus conventional fractionated radiotherapy in the palliation of painful bone metastases. Gulf J Oncolog. 2007;1(1):35-41.

10. Steenland E, Leer JW, van Houwelingen H, et al. The effect of a single fraction compared to multiple fractions on painful bone metastases: a global analysis of the Dutch Bone Metastasis Study. Radiother Oncol. 1999;52(2):101-109.

11. van der Linden YM, Steenland E, van Houwelingen HC, et al. Patients with a favourable prognosis are equally palliated with single and multiple fraction radiotherapy: results on survival in the Dutch Bone Metastasis Study. Radiother Oncol. 2006;78(3):245-253.

12. Arcangeli G, Giovinazzo G, Saracino B, et al. Radiation therapy in the management of symptomatic bone metastases: the effect of total dose and histology on pain relief and response duration. Int J Radiat Oncol Biol Phys. 1998;42(5):1119-1126.

13. Price P, Hoskin PJ, Easton D, Austin D, Palmer SG, Yarnold JR. Prospective randomised trial of single and multifraction radiotherapy schedules in the treatment of painful bony metastases. Radiother Oncol. 1986;6(4):247-255.

14. van der Linden YM, Lok JJ, Steenland E, et al. Single fraction radiotherapy is efficacious: a further analysis of the Dutch Bone Metastasis Study controlling for the influence of retreatment. Int J Radiat Oncol Biol Phys. 2004;59(2):528-537.

15. Niewald M, Tkocz HJ, Abel U, et al. Rapid course radiation therapy vs more standard treatment: a randomized trial for bone metastases. Int J Radiat Oncol Biol Phys. 1996;36(5):1085-1089.

16. Tong D, Gillick L, Hendrickson FR. The palliation of symptomatic osseous metastases: final results of the Study by the Radiation Therapy Oncology Group. Cancer. 1982;50(5):893-899.

17. Poulsen HS, Nielsen OS, Klee M, Rørth M. Palliative irradiation of bone metastases. Cancer Treat Rev. 1989;16(1):41-48.

18. Roos DE, Turner SL, O'Brien PC, et al. Randomized trial of 8 Gy in 1 versus $20 \mathrm{~Gy}$ in 5 fractions of radiotherapy for neuropathic pain due to bone metastases (Trans-Tasman Radiation Oncology Group, TROG 96.05). Radiother Oncol. 2005;75(1):54-63.

19. Bates T, Yarnold JR, Blitzer P, Nelson OS, Rubin P, Maher J. Bone metastasis consensus statement. Int J Radiat Oncol Biol Phys. 1992;23(1):215-216. 
20. Nielsen OS, Munro AJ, Tannock IF. Bone metastases: pathophysiology and management policy. J Clin Oncol. 1991;9(3):509-524.

21. Hartsell WF, Scott CB, Bruner DW, et al. Randomized trial of short- versus long-course radiotherapy for palliation of painful bone metastases. J Natl Cancer Inst. 2005;97(11):798-804.

22. Sande TA, Ruenes R, Lund JA, et al. Long-term follow-up of cancer patients receiving radiotherapy for bone metastases: results from a randomised multicentre trial. Radiother Oncol. 2009;91(2):261-266.

23. El-Shenshawy HMKA, El-Essawy A. The effect of a single fraction compared to multiple fractions radiotherapy on painful bone metastases with evaluation of computed tomography bone density in osteolytic bone metastases. Alexandria Journal of Medicine. 2006;42(2):439.

24. 8 Gy single fraction radiotherapy for the treatment of metastatic skeletal pain: randomised comparison with a multifraction schedule over 12 months of patient follow-up. Bone Pain Trial Working Party. Radiother Oncol. 1999;52(2):111-121.

25. Cole DJ. A randomized trial of a single treatment versus conventional fractionation in the palliative radiotherapy of painful bone metastases. Clin Oncol (R Coll Radiol). 1989;1(2):59-62.

26. Nielsen OS, Bentzen SM, Sandberg E, Gadeberg CC, Timothy AR. Randomized trial of single dose versus fractionated palliative radiotherapy of bone metastases. Radiother Oncol. 1998;47(3):233-240.

27. Foro Arnalot P, Fontanals AV, Galcerán JC, et al. Randomized clinical trial with two palliative radiotherapy regimens in painful bone metastases: 30 Gy in 10 fractions compared with $8 \mathrm{~Gy}$ in single fraction. Radiother Oncol. 2008;89(2):150-155.

28. Kaasa S, Brenne E, Lund JA, et al. Prospective randomised multicenter trial on single fraction radiotherapy $(8 \mathrm{~Gy} \times 1)$ versus multiple fractions $(3 \mathrm{~Gy} \times 10)$ in the treatment of painful bone metastases. Radiother Oncol. 2006;79(3):278-284.
29. Konski A, James J, Hartsell W, et al. Economic analysis of radiation therapy oncology group 97-14: multiple versus single fraction radiation treatment of patients with bone metastases. Am J Clin Oncol. 2009;32(4):423-428.

30. Pollicino CA, Turner SL, Roos DE, O'Brien PC. Costing the components of pain management: analysis of Trans-Tasman Radiation Oncology Group trial (TROG 96.05): one versus five fractions for neuropathic bone pain. Radiother Oncol. 2005;76(3):264-269.

31. van den Hout WB, van der Linden YM, Steenland E, et al. Single- versus multiple-fraction radiotherapy in patients with painful bone metastases: cost-utility analysis based on a randomized trial. J Natl Cancer Inst. 2003;95(3):222-229.

32. Konski A. Radiotherapy is a cost-effective palliative treatment for patients with bone metastasis from prostate cancer. Int J Rad Oncol Biol Phys. 2004;60(5):1373-1378.

33. Lutz S, Berk L, Chang E, et al. Palliative radiotherapy for bone metastases: an ASTRO evidence-based guideline. Int $J$ Radiat Oncol Biol Phys. 2011;79(4):965-976.

34. Amouzegar-Hashemi F, Behrouzi H, Kazemian A, Zarpak B, Haddad P. Single versus multiple fractions of palliative radiotherapy for bone metastases: a randomized clinical trial in Iranian patients. Curr Oncol. 2008;15(3):151.

35. Sarkar SK, Sarkar S, Pahari B, Majumdar D. Multiple and single fraction palliative radiotherapy in bone secondaries a prospective study. Indian Journal of Radiology and Imaging. 2002;12(2):281-284.

36. Safwat E, El-Nahas T, Metwally H, Abdelmotgally R, Kassem N. Palliative fractionated radiotherapy for bone metastases clinical and biological assessment of single versus multiple fractions. J Egypt Natl Canc Inst. 2007;19(1):21-27.
Cancer Management and Research

\section{Publish your work in this journal}

Cancer Management and Research is an international, peer-reviewed open access journal focusing on cancer research and the optimal use of preventative and integrated treatment interventions to achieve improved outcomes, enhanced survival and quality of life for the cancer patient The journal welcomes original research, clinical \& epidemiological

\section{Dovepress}

studies, reviews \& evaluations, guidelines, expert opinion \& commentary, case reports \& extended reports. The manuscript management system is completely online and includes a very quick and fair peerreview system, which is all easy to use. Visit http://www.dovepress.com/ testimonials.php to read real quotes from published authors. 